\title{
THE ARTHROPOD-BORNE ENCEPHALITIS VIRUSES, THE NEGLECTED SERIOUS DISEASES
}

By

MOSTAFA M. ELNAKIB ${ }^{1}$, EMAN EBRAHIM ABDEL FADIL ${ }^{1}$

And TOSSON A. MORSY ${ }^{2}$

Military Medical Academy Cairo $11291^{1}$ and Department of Parasitology, Faculty of Medicine, Ain Shams University, Cairo $11566^{2}$, Egypt

\section{Abstract}

Arthropod-borne encephalitis viruses are highly adapted to a particular reservoir host. Viruses spread from animal to animal by an infected specific mosquito or tick species. Mosquito or tick becomes infected when feeding on the viremic animal blood. Virus then replicates in the vector, ultimately infecting the salivary glands, which transmits the virus to a new host with infective saliva while taking a blood meal. Infected patients may become ill; they usually do not develop sufficient viremia to infect feeding vectors, and thus do not contribute to the transmission cycle.

Among mosquito-borne encephalitis, the greatest public health threat in North America and is posed by the West Nile, St. Louis encephalitis, and La Crosse encephalitis viruses. Venezuelan equine encephalitis virus is of concern in Central and South America, while Japanese encephalitis virus affects residents or visitors to parts of Asia. Among the tick-borne encephalitis, tick-borne Encephalitis virus causes the greatest public health threat among residents or visitors to Eastern Europe and Asia.

Eastern equine encephalitis (EEE) virus is widely distributed throughout North, Central, and South America and the Caribbean. EEE virus is the most severe one, with mortality up to $30 \%$.Western equine encephalitis (WEE) virus is a found in North and South America and is a potential agent of bioterrorism through the aerosol route. Case fatality rate is 3 to $7 \%$, .La Crosse virus (LAC) is the most pathogenic member of California encephalitis serogroup in central and eastern United States, mostly in school-aged children. Most infections are asymptomatic with low mortality rates. Treatment is supportive, with emphasis on control of cerebral edema and seizures. Murray Valley encephalitis (MVE) virus occurs in Australia, New Guinea, and probably islands in the eastern part of the Indonesian archipelago. MVE virus is maintained in a natural cycle involving water birds and Culex annulirostris. Only 1 in 1000 to 2000 infections had clinical illness; but, about one-third of patients die and about half the survivors suffered from neurologic deficits. Venezuelan equine encephalitis (VEE) widely spread from Florida to South America, occur periodically, but occasionally, large epidemics occur among equine and humans. VEE is infectious via aerosols, making it an occupational risk to certain laboratory workers and a potential agent of bioterrorism. Effective prevention by immunizing equines, which serve as the primary amplification hosts for the epizootic VEE viruses. Tick-borne encephalitis (TBE) exists over a wide geographical area, including Russia and Europe. Human exposure occurs through work or recreational activities when the ticks are most active. TBE virus is transmitted from the saliva of an infected tick while taking blood meal. Case fatality rates range from 2 to $8 \%$, Treatment is mainly supportive.

In Middle Eastern Countries, no proper reported statistics, although the climatic environment favors the spreading of both the vectors and the viruses. So, it is advisable to make diagnostic techniques readily available and more public health awareness of those risky, potentially fatal infectious diseases. Already Dengue viral hemorrhagic fever is mostly responsible for major worldwide fatalities as well as West Nile Fever already present there from before, without specific treatment or vaccine available. Keywords: Arthropod-borne viral encephalitis, General review, Discussion, Recommendations.

\section{Introduction}

Encephalitis is irritation and swelling (inflammation) of the brain, most often due to infections by a virus, bacterium or fungus (infectious encephalitis, or primary encephalitis), or when the immune system responds to a previous infection; the immune system mistakenly attacks brain tissue (secondary encephalitis, or post-infectious encephalitis).

The arthropod-borne encephalitis viruses are significant public health problem worldwide, usually highly adapted to specific reservoir hosts and are spread from animal to animal or humans by bite of an infected art- 
hropod, usually a specific mosquito species or tick species.

\section{Review and Discussion}

The natural animal hosts of these viruses usually remain unaffected and viral circulation generally remains undetected until one of the following occurs: 1- Humans encroach on the natural enzootic focus, 2- Environmental conditions favor substantial amplification in the primary vector-host cycle causing sufficient number of vectors to become infected so human risk is increased, and 3- The virus escapes the primary cycle via a secondary vector or vertebrate host, thereby bringing infected, human-biting vectors in close proximity to human habitation. Although infected humans may become ill, they usually do not develop sufficient viremia to infect feeding vectors. As a result, humans do not usually contribute to the transmission cycle. The mosquito or tick becomes infected when feeding on the blood of the viremic animal. The virus then replicates in the mosquito or tick, then to salivary glands transmiting the virus to a new host as humans while taking a blood meal.

Geographic Distribution: Among the mosquito-borne encephalitis viruses, the greatest public health threat in North America is posed by the West Nile, St. Louis encephalitis and La Crosse encephalitis viruses. Venezuelan equine encephalitis virus is of concern in Central and South America, while the Japanese encephalitis virus affects persons living or traveling to parts of Asia. Dengue is a rare cause of encephalitis throughout the tropical world but rather a major illness through viral hemorrhagic fever. Among the tick-borne viruses that cause encephalitis, tick-borne encephalitis virus has the greatest public health impact worldwide and is of concern to residents of or visitors to northern parts of Eastern Europe and Asia. The Powassan virus is a rare, but tick-borne cause of encephalitis in the north central and northeastern parts of the United States, eastern Canada, and Russia.
Cross-Reactivity: The close antigenic relationships among the flaviviruses may cause a diagnosis problem. Individuals who have been recently vaccinated with yellow fever, tick borne encephalitis virus, or Japanese encephalitis vaccines or who have been recently infected with a related flavivirus may have a positive serologic test to one or more flaviviruses not causing the current illness. Plaque reduction neutralization test (PRNT), which was the most specific test for the arthropod-borne flaviviruses, may be identified serologic cross-reactions among the flaviviruses. But, some degree of cross-reaction in neutralizing antibody may still cause ambiguous results. Cross re-activities of the bunyaviruses and togaviruses causing encephalitis is not as extensive.

1- West Nile virus encephalitis (WN) virus, a member of the Japanese encephalitis virus antigenic complex, was first isolated in a blood sample in a patient from the West Nile province of Uganda in 1937. This RNA virus was initially considered of minor public health importance (Gubler, 2007). It emerged from obscurity in 1999 when the first incursion of the virus into North America caused 62 cases of encephalitis and seven deaths in New York. Since that time, the virus has dramatically spread, and $\mathrm{WN}$ virus activity has now been detected in all 48 continental states, the District of Columbia, and Puerto Rico. WN virus causes both sporadic infection and outbreaks that may be associated with severe neurologic disease (Petersen and Hayes, 2008). WN virus is one of the most widely distributed of all arboviruses with an extensive distribution in the Old World, throughout Africa, the Middle East, parts of Europe and the former Soviet Union, South Asia, and Australia. The virus had not been detected in the Americas before the 1999 New York City outbreak. WN virus strain of United States is nearly genetically identical to a virus identified in Israel, Kuwait, Lebanon, Saudi Arabia, Sudan, and the United Arab Emirates (Gossner et al, 2017). Also, transmission was described via 
transfused blood, red blood cells, platelets, and fresh frozen plasma but a small residual risk remains from donations with low viremia not detected by nucleic acid detection tests (NAT) tested in the mini-pool format used by blood centers. Transmission was reported by transplanted organs, transplacental transmission, percutaneous occupational transmission, conjunctiva exposure, and in a dialysis center by the unidentified means. The transmission via breast milk was proved (Johnson et al, 2006).

In Egypt, more than 110 mosquito species and subspecies (Mikhail et al, 2009; El Bahnasawy et al, 2013a) and more than 32 tick genera were reported (Hoogstraal, 1954). About 150 migratory birds' species (can act as hosts) visit Egypt annually (Mazyad et al, 1999) in addition to 350 resident ones besides WN in man and animals was reported (El-Bahnasawy et al, 2013b).

2- St. Louis encephalitis (SLE) is an acute, mosquito-borne viral illness characterized by meningeal and brain parenchymal inflame-mation and injury. The disease occurs in endemic and epidemic form in North and South America. Epidemics of SLE in the United States have been responsible for at least $1,000,000$ mild or subclinical infections, 10,000 clinical cases, and 1000 deaths in the United States since SLE virus was first isolated in 1933 during an outbreak in St. Louis, Missouri (Reisen, 2003). Studies of SLE virus evolution indicate that the virus was introduced into North America from tropical America in the late $19^{\text {th }}$ Century (Baillie et al, 2008). There is evidence that West Nile virus, which was introduced into the United States in 1999, is displacing SLE in some areas by more efficient transmission and cross-protective immunity in wild birds (Reisen et al, 2008). St. Louis encephalitis virus is a member of the family Flaviviridae, a group of small (40 to $60 \mathrm{~nm}$ ), enveloped, positive-sense, single-stranded RNA viruses that replicate in the cytoplasm of infected cells. Other members of this virus family include West Nile virus, Japanese encephali- tis virus, Murray Valley encephalitis virus, yellow fever virus, and dengue virus (May et al, 2008). SLE virus strains from the eastern and western United States and from tropical America are distinguishable at the nucleotide sequence level into at least six lineages and multiple clades (Kramer and Chandler, 2001) and differ with respect to the mosquito vectors responsible for transmission and virulence for animal models (Trent et al, 1980). SLE virus Lineage II present east of the Mississippi river has been associated with severe epidemics, has the highest virulence for laboratory animals, and the highest case-fatality rate for humans. While there is evidence for the geographic separation and the local persistence (through overwintering), mainly in California (Lineage I), analyses of SLE virus evolution suggests flow of neotropical strains, particularly from northern Central America, Mexico, and the Caribbean, into the US by migratory birds (Auguste et al, 2009).

SLE causes alymphocytic meningitis; pathhologic changes in the brain, particularly gray matter, include perivascular lymphocytic infiltrates, cellular nodules, and neuronal degeneration. While lesions are distributed throughout the brain, the most severely affected regions are the hypothalamus, cerebellar and cerebral cortex, basal ganglia, brainstem and cervical spinal cord (Gardner and Reyes, 1980). Rarely, SLE may present as acute demyelinating encephalomyelitis (ADEM) with prominent lesions in white matter, but pathologic changes in extraneural tissues were not reported (Sejvar et al, 2004).

Clinically, SLE may be difficult to differen-tiate from other causes of summer season encephalitis, including West Nile. Flaccid paralysis and polio-like syndrome are more common in West Nile. SLE diagnosis is serology, particularly ELISA-IgM. Presence of IgM antibodies in a single serum provides a presumptive diagnosis, and a significant rise or fall between appropriately timed acuteconvalesscent or early-late convalescent sera 
is diagnostic. But, antigenic cross-reactions with other flaviviruses, particularly West Nile virus, can be a problem, although use of a discriminatory algorithm for analysis of IgM successfully differentiated infections (Martin et al, 2004). Non-infectious recombinant virus-like particle antigens are useful as diagnostic reagents.

No specific antiviral therapy was efficacy and corticosteroids are not indicated, except in the rare case of ADEM. Interferon Alfa reduced mortality in mice when it is given either subcutaneously or by aerosol at the time of exposure to the virus (Brooks and Phillpotts, 1999). The potential efficacy of this approach in humans was evaluated in a pilot study in which 15 patients with SLE received interferon alfa- $2 b$ were compared to 17 untreated patients with SLE admitted to the same hospital during an outbreak (Rahal et al, 2004). There is no available vaccine, although several experimental studies showed promise, including chimeric attenuated virus vectors using yellow fever 17D and vesicular stomatitis viruses. Testing can be done to observe potential virus transmission between birds and mosquitoes and initiate mosquito control measures before appearance of human cases. Mosquito control is also a must.

3- Dengue virus infection: Aedes-borne diseases (Dengue, Chikungunya, Yellow Fever and Zika) are an emerging problem worldwide, escalating overall risk and burden of disease worldwide. Dengue viruses are members of the family Flaviviridae, genus flavi-virus with four anti-genically related but distinct viruses; all are mosquitoborne human pathogens. Apart from the Aedes, nosocomial transmission via blood donors and needle-stich injury was reported (Morsy, 2018). The four dengue virus serotypes are associated with fever, rash, and the more severe forms, hemorrhagic fever and shock syndrome (Kroeger et al, 2004). The symptomatic dengue virus infections can present with a wide range of clinical manifestations, from self-limited dengue fever to dengue hemorrhagic fever with shock syndrome, which carries a high mortali-

ty rate. The risk of severe disease is much higher in sequential rather than primary dengue infection (Deen et al, 2008). Classic dengue fever (DF) is an acute febrile illness accompanied by headache, retroorbital pain, and marked muscle and joint pains, which evoked the term break-bone fever (RigauPerez, 1998). Fever typically lasts for five to seven days. Hemorrhagic manifestations can also occur in patients with DF. Physical examination is non-specific, but may include a macular or maculo-papular rash in approximately $50 \%$ of cases (Halstead, 2007). Dengue hemorrhagic fever (DHF) is the most serious manifestation of dengue virus infection and can be associated with shock. The four cardinal features of DHF include increased vascular permeability, fever, hemorrhage, and marked thrombocytopenia; less than 100,000cells/ $\mathrm{mm}^{3}$ (WHO, 1997). The plasma leakage is the most specific and lifethreatening feature of DHF and usually occurs rapidly over a period of hours and can lead to shock. Severe plasma leakage can occur in patients with minimal hemorrhagic manifestations (Khor et al, 2006). Hemorrhagic manifestations of dengue virus infection can range from spontaneous petechiae to profuse bleeding. Severe bleeding sometimes occurs in the absence of plasma leakage (Chhour et al, 2002). Diagnosis of acute dengue virus infection is based mainly on clinical signs and symptoms in endemic countries. In countries where serologic assays are available, an acute phase serum plasma sample for use in the IgM immunoassay (MAC-ELISA or equivalent) as a choice procedure was recommended (McBride et al, 1998). If the clinical suspicion of dengue infection was high and assay was negative, testing paired acute and convalescent sera by hemagglutination inhibition or ELISA was recommended.

Dengue may be resurging in MENA (middle east-north Africa) (WHO, 2014) with also, outbreaks occurred in Pakistan and the 
Arabian Peninsula, Somalia, Sudan (Arya and Agarwal, 2014) and an outbreak in Egypt that occurred following the decadeslong absence of reported cases (WHO, 2015). Despite increasing global concern about the Aedes-transmitted arboviruses threat, the dengue epidemiology in the MENA region was largely uncharacterized (Humphrey et al, 2016).

4- Eastern Equine Encephalitis Virus: Eastern equine encephalitis (EEE) virus (family Togaviridae, genus Alphavirus) is widely distributed throughout North, Central, and South America and the Caribbean. Four genetic lineages exist: Subtype I in North America and the Caribbean, and subtypes II to IV in South and Central America. While subtype I is associated with severe clinical disease, subtypes II to IV are not clearly associated with human disease. In North America, wild birds and Culiseta melanura, a mosquito that is found in swamp areas that support cedar, red maple and loblolly bay trees, maintain the virus. The ecology of South American EEE strains is not well described. Laboratory-acquired infections have occurred, and EEE virus is a potential agent of bioterrorism through the aerosol route (Arrigo et al, 2010).

Human infections sporadically peak mainly in August and September with small outbreaks each summer, mostly along the Atlantic and Gulf coasts of United States. From 1964 to 2010, 270 cases of EEE were reported, with the largest number of cases identified in Florida, Georgia, Massachusetts, and New Jersey. In 2005, 21 cases were reported, which included an outbreak of 11 cases (with four fatalities) in New Hampshire and Massachusetts. All patients had resided in a wooded area within a half mile of a swamp or cranberry bog (CDC, 2006).

Clinical manifestations: The incubation period usually exceeds one week after the mosquito bite. The illness often begins with a prodrome lasting several days, with fever, headache, nausea and vomiting being com- mon. Approximately two percent of infected adults and six percent of infected children develop encephalitis. Once neurologic symptoms begin, the clinical condition deteriorates rapidly, with approximately $90 \%$ becoming comatose or stuporous. Seizures, and focal neurologic signs, including cranial nerve palsies, develop in approximately onehalf the patients. Leukocytosis and hyponatremia are common on laboratory testing.

Cerebrospinal fluid (CSF) analysis typically shows pleocytosis, often with a neutrophilic predominance and elevated protein concentration. An elevated white cell count in initial CSF examination and hyponatremia correlate with a poor prognosis. Electroencephalography revealed generalized slowing and disorganization of the background, and epileptiform discharges was seen. Magnetic resonance imaging (MRI) proved more sensitive than computed tomography (CT). Both were often abnormal early in the course, with focal lesions in the basal ganglia, thalami, and brainstem being particularly common. Cortical lesions, meningeal enhancement, and periventricular white-matter changes were less common (Deresiewicz et al, 1997).

EEE diagnosis can be made by demonstration of $\operatorname{IgM}$ antibody by capture immuneassay of CSF, a fourfold rise in serum antibody titers against EEE virus, or isolation of virus from or demonstration of viral antigen or genomic sequences in tissue, blood, or CSF. Serum IgM antibodies alone should be confirmed by demonstration of IgG antibody by another serologic assay (e.g., neutralization or hemagglutination inhibition (Panzig et al, 1978).

Outcome: EEE virus is the most severe of the arboviral encephalitides, with a mortality of at least $30 \%$. Death can occur within three to five days of onset and, among survivors, complete recovery is uncommon. Sequelae include convulsions, paralysis, and mental retardation. EEE in South America is less severe. No specific therapy for EEE. Inactivated vaccines have been successful in hors- 
es and an inactivated vaccine has been used in laboratory workers or others at high risk of exposure, but is not commercially available. No specific treatment is available. One patient may have benefited from IVIG therapy (Golomb et al, 2001). Prevention focuses on avoidance of mosquito bites and mosquito control in suburban areas.

5- Western Equine Encephalitis Virus: Wes- tern equine encephalitis (WEE) virus (family Togaviridae, genus Alphavirus) is a complex of closely related viruses found in North and South America. Flooding, which increases breeding of Culex mosquitoes, may precipitate summer outbreaks. Large out-breaks in humans and horses occurred in the western United States in the 1950s \& 1960s. But, a declining horse population, equine vaccination, and improved vector control reduced its incidence. WEE is an agent of bioterrorism through the aerosol route (Sewell, 2003). Less than 1 in 1000 infected adults develop ence-phalitis, but the frequency is greater in children, particularly infants. Following an incubation period of about seven days, headache, vomiting, stiff neck, and backache are typical; restlessness, irritability, and seizures were commonest in children. Although rare in adults and older children, neurologic sequelae are relatively common in infants and case fatality rate was 3 to $7 \%$ (Calisher, 1994).

Diagnosis of the WEE can be made by demonstration of IgM antibody by capture immunoassay of CSF, a fourfold rise in serum antibody titers against WEE virus, or isolation of virus from or demonstration of viral antigen or genomic sequences in tissue, blood, or CSF. Serum IgM antibodies alone must be confirmed by detection of IgG antibody by another serologic assay as neutralization or hemagglutination inhibition (Arnold et al, 1984). Prevention focuses on mosquito control and avoids mosquito bites. Inactivated vaccine is available for horses. Although inactivated vaccine was used for laboratory staff and others at high risk of exposure, but it was not commercially available. Specific treatment is not available.

6- Japanese encephalitis virus (JEV), a mosquito-borne flavivirus, is the most important cause of viral encephalitis in Asia based on its frequency and severity and about 50,000 cases of JEV were estimated to occur each year. With the near eradication of poliomyelitis, JEV is now the cause of childhood viral neurological infection and disability in Asia (Halstead, and Jacobson, 2003). JEV is closely related to West Nile, St. Louis encephalitis, and Murray Valley encephalitis viruses. It affects children $<15$ years of age; by early adulthood the majority of the population has protective immunity following natural exposure to JEV as a result of ongoing environmental transmission Among immunologically naïve travelers visiting endemic regions, the disease can affect individuals at any age. JEV is transmitted in an enzootic cycle involving mosquitoes and vertebrate amplifying hosts, primarily pigs and wading birds, and man is incidental and dead end hosts in transmission cycle, as they do not develop sufficiently high viremia to infect feeding mosquitoes (MacKenzie et al, 2007). The commonest recognized clinical presentation is acute encephalitis. Milder forms of disease such as aseptic meningitis or non-specific febrile illness with headache also occur. Seizures (usually generalized tonic-clonic) are very common, especially among children. JE is diagnosed by serologic detection of JEV-specific IgM antibody in CSF or serum by an antibody capture ELISA. JEV-specific IgM antibodies in CSF proved recent CNS infection. IgM antibody in serum is suggestive of JE but could indicate asymptomatic infection or recent JE. Precautions among travelers to endemic regions include personal protective measures to prevent mosquito bites. For some travelers to a high risk setting based on location, duration, season, and activities, JE vaccine may further minimize the risk of infection vaccination (Sakagguchi et al, 2001). 
7- La Crosse Encephalitis Virus: La Crosse virus (LAC, family Bunyaviridae, genus Bunyavirus) is the most pathogenic member of the California encephalitis serogroup, which includes the California encephalitis, trivittatus, snowshoe hare, and Jamestown Canyon viruses. LAC is transmitted via $\mathrm{Ae}$ des triseriatus (eastern tree hole mosquito), and mammalian hosts include the eastern chipmunk, tree squirrels, and foxes. In addition, epidemiologic evidence suggests that the newly introduced Ae. albopictus mosquito (Asian tiger mosquito) may be an important vector of man. Human infections occur in the central and eastern United States, mostly in school-aged children from July through September. Most of the infections were asymptomatic (Hotez, 2018)

After an incubation period of three to seven days, were evaluated in a review of 127 patients who required hospitalization. The following findings were noted (Erwin et al, 2002): a- All of the patients were schoolaged children (range 0.5 to 15 years), bHeadache, fever, and vomiting were each present in at least $70 \%$ of patients and disorientation in $42 \%$, c- Seizures occurred in $46 \%, 62 \%$ of which had have a focal component and $24 \%$ of which progressed to status epilepticus, d- Approximately $20 \%$ had focal neurologic abnormalities. The findings of fever, focal neurologic signs, and focal seizures mimic herpes simplex encephalitis,virus type 1 (HSV-1) encephalitis which is the most common cause of sporadic fatal encephalitis worldwide and is often characterized by rapid onset of fever, headache, seizures, focal neurologic signs, and impaired consciousness and involves all age groups. Beyond the neonatal period, the etiologic agent is herpes simplex virus type 1 (Hjalmarsson et al, 2007). In neonates, herpes encephalitis may be caused by either HSV -1 or HSV-2. The clinical syndrome is often characterized by the rapid onset of fever, headache, seizures, focal neurologic signs, and impaired consciousness, f- Aseptic meningitis alone, without evidence of encephalitis, occurred in $13 \%$ of LAC gHyponatremia was present in $21 \%$ and was present in all 13 patients (11\%) whose condition deteriorated in the hospital, and $12 \%$ of children had resi-dual focal neurologic, cognitive, and behavi- orral deficits. Leukocytosis was common, with polymorphonuclear cells predominating. CSF showed pleocytosis with either neutrophilic or lymphocytic predominance. EEG is abnormal in two-thirds of patients, mainly with slowing or epileptic-form discharges. Focal features or periodic lateralizing epileptiform discharges, usually with involvement of the temporal lobe, may suggest herpes simplex encephalitis. CT scan was generally nor-mal, but might show generalized cerebral ede-ma. MRI may show focal areas of gadolinium enhancement (Yahr, 1972).

Diagnosis of LAC can be made by demonstration of IgM antibody by capture immunoassay of CSF, a fourfold rise in serum antibody titers against LAC virus, or isolation of virus from or detection of viral antigen or genomic sequences in tissue, blood, or CSF. Viral isolation from CSF is rare. Serum IgM antibodies alone must be confirmed by demonstration of IgG antibody by another serologic assay as neutralization (Persijn et $a l, 2011)$. Treatment is supportive, with emphasis on control of cerebral edema and seizures (Mc-Junkin et al, 2001). Ribavirin was used, but efficacy was unproven at least for children (McJunkin et al, 1997).

Prevention rests on avoidance of mosquito bites. A case of possible congenital infection has also been reported with $\operatorname{IgM}$ antibodies identified in the umbilical cord blood; however, the newborn was asymptomatic and development was normal. No seroconversion was documented in this case because the mother declined further testing (CDC, 2009).

8- Murray Valley Encephalitis: Murray Valley encephalitis (MVE) virus (family Flaviviridae, genus Flavivirus), occurs in Australia, New Guinea, and probably islands in the eastern part of the Indonesian archi- 
pelago. MVE virus is believed to be maintained in a natural cycle involving water birds and Culex annulirostris mosquitoes. Viremia was not documented in humans, who are likely dead-end hosts (Mackenzie et al, 1994).

Only one in 1000 to 2000 infections results in clinical illness, which resembles Japanese encephalitis. There is usually a prodromal illness with headache, fever, nausea and vomiting, anorexia, and myalgias, followed by drowsiness, malaise, irritability, mental confusion, and meningismus. Seizures are more common in children. In severe cases, there may be hyperactive reflexes, spastic paresis, seizures, coma, and death (Burrow et al, 1998). CT scan was normal in about two-thirds of patients. Reported abnormalities include mild hydrocephalus, cerebral edema, reduced attenuation extending from the thalami to the brainstem, and cerebral atrophy (Kienzle and Boyes, 2003).

Diagnosis of MVE was be made by detection of IgM antibody immunoassay of CSF, a fourfold raised in serum antibody titers against MVE virus, or isolation of virus from or demonstration of viral antigen or genomic sequences in tissue, blood, or CSF. Serum IgM antibodies alone should be confirmed by demonstration of $\operatorname{IgG}$ antibody by another serologic assay (e.g., neutralization or hemagglutination inhibition (CDC, 1997).

About one-third of patients with MVE die and about half the survivors have residual neurologic deficits. Children and the elderly are at highest risk as there was no vaccine for MVE virus. Prevention relies on mosquito control and avoidance of mosquito bites.

9- Venezuelan Equine Encephalitis Virus: Six subtypes (I-VI) within the Venezuelan equine encephalitis (VEE) virus (family Togaviridae, genus Alpha virus) complex. Five antigenic variants exist within subtype I (IAB, IC, ID, IE, IF). These subtypes and variants are classified as epizootic (can produce outbreaks of illness in animals) or enzootic (infects animals in a region, but often produces asymptomatic or sporadic illness in animals), based upon their apparent virulence and epidemiology: a- Epizootic variants of subtype I (IAB \& IC) cause equine epizootics and are associated with more severe human disease, and b- Enzootic strains: ID-F, II [Everglades], III [Mucambo, Tonate], IV [Pixuna], V [Ca-bassou], VI [Rio Negro]) do not cause epizootics in horses, but produce sporadic disease in humans.

Epizootic strains are transmitted by many mosquitoes, and enzootic strains by Culex species.

VEE has a widespread geographic distribution from Florida to South America, where it is an important veterinary and public health problem. Focal outbreaks or large regional epidemics occur, with thousands of equine and human infections. VEE is infectious via aerosols, making it an occupational risk to certain laboratory workers and a potential agent of bioterrorism.

After an incubation period of one to six days, there is a brief febrile illness of sudden onset, characterized by malaise, nausea or vomiting, headache, and myalgia. Less than $0.5 \%$ of adults and less than $4 \%$ of children developed encephalitis, characterized by nuchal rigidity, seizures, coma, and paralysis. Long-term sequelae and fatalities are uncommon. Diagnosis of VEE can be made by demonstration of $\operatorname{IgM}$ antibody by capture immunoassay of CSF, a fourfold rise in serum antibody titers against SLE virus, or isolation of virus from or demonstration of viral antigen or genomic sequences in tissue, blood, or CSF. Viremia was usually not detectable in serum. Serum IgM antibodies alone should be confirmed by demonstration of IgG antibody by another serologic assay e.g., neutralization or hemagglutination inhibition (CDC, 1997).

Effective prevention of both human and equine disease can be accomplished by immunizing equines, which serve as the primary amplification hosts for the epizootic VEE viruses and without which there would be little human disease. During the epidemics, mosquito vectors can be controlled by insec- 
ticides. Live attenuated and inactivated vaccines have been used for laboratory workers; however, human vaccines are not commercially available.

10- Tick-Borne Encephalitis Virus: Tickborne encephalitis (TBE) is caused by three closely related viruses (family Flaviviridae, genus Flavivirus): a- The Russian springsummer encephalitis subtype (also called far eastern subtype), b- The Siberian subtype also called Vasi-lchenko virus, and c- The Central European encephalitis subtype (also called western subtype (Kaiser, 2008).

Vector: These viruses are maintained in natural cycles involving a variety of mammals and ticks. Ixodes persulcatus and Ix. ricinus are vectors in Russia and Europe, respectively. Ixodes ovatus is the vector in Hokkaido. Tick-borne encephalitis exists over a wide geographical area (Süss, 2003).

Transmission: Human exposure occurs through work or recreational activities in the spring and summer months in temperate zones and in fall and winter in the Mediterranean, when the ticks are most active. TBE virus is transmitted from the saliva of an infected tick within minutes of the bite; early removal of the tick may not prevent encephalitis. In Europe, tick activity starts in the spring and declines in the fall. Nymphal forms of $I$. ricinus are most important in human transmission whereas adult ticks are the dominant vector for I. persulcatus. Outbreaks occurred occasionally followed ingestion of unpasteurized milk products from infected sheep and goats (Zajkowska, 2010).

Age, severity of illness in the acute stage, and low initial neutralizing antibody titers are associated with illness severity. The CCR5 delta 32 allele may predispose individuals to TBE (Mickiene et al, 2014). The CCR5 and CXCR4 are the major chemokine coreceptors used by HIV to enter into human lymphocytes. HIV isolates were classified as CCR5-tropic (R5), CXCR4-tropic (X4), or dual tropic (R5/X4) strains. Some progress from virus transmission to late stage in the AIDS patients within two years. Others are chronic longterm progresses who maintain low viral loads and normal CD4 counts for $>10$ years without treatment and there are "elite suppressors" who have VL $<50 \mathrm{c} / \mathrm{mL}$ without therapy (CDC, 2006). The rate of disease progression appear to be related to the genetic regulation of immunologic control of HIV and medication adherence, besides the rate of progression are older age, viral variants, substance abuse, nutritional status of the host, active tuberculosis. The need for HAART treatment may be life-long once initiated (Williams et al, 2006).

Clinical manifestations: The incubation period of TBE generally lasts between 7 and 14 days and approximately two-thirds of patients reported tick bite. The disease is characterized by a biphasic illness. In the first viremic pha-se, fever, fatigue, malaise, headache, and arth-ralgia predominate (Vilibić-Čavlek et al, 2014). Neurological symptoms hallmark the second phase, ranging from mild meningitis to severe encephalitis, which may be accompanied by myelitis and acute flaccid paralysis (Lessell and Collins, 2003). Reports of chronic and progressive disease were noted primarily with the Siberian subtype; however, this was uncommonly (CDC, 1998).

Diagnosis of the CSF examination generally shows pleocytosis. Although polymorphonuclear cells may predominate at first, the CSF profile is later marked by dominance of mono nuclear cells (Lindquist and Vapalahti, 2008). Diagnosis of TBE can be made by demonstration of IgM antibody by capture immunoassay of CSF, a fourfold rise in serum antibody titers against TBE virus, or isolation of virus from or demonstration of viral antigen or genomic sequences in tissue, blood, or CSF. Serum IgM antibodies alone must be confirmed by detection of IgG antibody by another neutralization test (Holzmann, 2003). MRI abnormalities could be noted in approximately $18 \%$ of patients with lesions located in the thalamus, cerebellum, brainstem, and caudate nucleus; EEG is abnormal in $77 \%$ of patients. Both modalities 
gave only non-specific findings (Kindberg et al, 2008).

Outcome: Case fatality rates with the Siberian subtype rarely exceed $8 \%$ and there is a greater tendency to developing nonparalytic encephalitis and chronic TBE. In comparison, the western European subtype typically produces the biphasic form and tends to be less severe, with case fatality rates of 1 to $2 \%$. Children have a more favorable prognosis than adults. Up to one-half of patients report symptoms 6 to 12 months post-encephalitis, with severe impairment reported in 30\% (Haglund and Günther, 2003).

Treatment is mainly supportive. In a large study of 709 patients with TBE in Germany, $12 \%$ of patients required intensive care and $5 \%$ required assisted ventilation. Of 230 patients who had subsequent examination at a later time, approximately one-quarter had moderate to severe sequelae (Kaiser, 1999).

Effective vaccines are available in Europe and from many travel clinics in Canada; vaccines are not available in the United States. Mass vaccination has been undertaken in Austria, with protection rates of at least 96\% (Barrett et al, 2003). Between the early 1970 s and early 1980s, the average TBE incidence rate was 5.7 per 100,000; it dropped to 0.9 per 100,000 between the mid1990s \& 2005 among vaccinated individuals, but remained high (6 per 100,000) among unvaccinated individuals (Heinz et al, 2013).

Travelers with extensive outdoor exposures from camping or related activities in endemic regions during the spring and summer months must be vaccinated. (See CDC, 2017: Travel Book Immunizations section).

11- Powassan virus, a member of the tickborne encephalitis group of flaviviruses, encompasses 2 lineages with separate enzootic cycles. The prototype lineage of Powassan virus (POWV) is principally maintained bet ween Ixodes cookei ticks and the groundhog (Marmota momax) or striped skunk (Mephitis mephitis), whereas the deer tick virus (DTV) lineage is believed to be maintained between Ixodes scapularis ticks and the white-footed mouse (Peromyscus leucopus). It was isolated from four tick species: Ixodes cookie, Ix. narxi, Ix. spinipalpus, and Dermacentor andersoni (El Khoury et al, 2013).

Powassan virus is a rare cause of encephalitis in eastern Canada and the north central and northeastern United States. There were more than 30 case reports since its discovery in 1958 (Gholam et al, 1999)._However, serologic surveys have found an antibody prevalence of 1 to $4 \%$, indicating that asymptomatic infection is common. Infection mostly occurs from June to September. The reported incubation periods ranged from eight to 34 days (CDC, 2001). But, few patients recall a tick bite, since Ixodid ticks are small and can be easily overlooked. Symptomatic patients typically present with fever, weakness, somnolence, gastrointestinal complaints, headache, and confusion, and seizures can occur.

Serum and cerebrospinal fluid samples can be tested for IgM and neutralizing antibodies. The diagnosis of Powassan virus infection can be made by demonstration of $\operatorname{IgM}$ antibody by capture immunoassay of CSF, a fourfold rise in serum antibody titers against the virus, or isolation of virus from or the demonstration of viral antigen or genomic sequences in tissue, blood, or CSF. Serum $\operatorname{IgM}$ antibodies alone should be confirmed by demonstration of IgG antibody by another serologic assay (e.g., neutralization). The case-fatality rate is 5 to $10 \%$, with a high incidence of residual neurological dysfunction among survivors, which including hemiplegia, headaches, minor memory impairment, and persistent ophthalmoplegia (Hinten et al, 2008).

There is no specific treatment or vaccine. Prevention of tick bites by using repellents, avoiding or clearing brushy areas, wearing light colored clothing may be effective. Removing ticks soon after outdoor exposure is advisable.

The so-called deer tick virus is likely an antigenic subtype of Powassan virus and is maintained in Ix. scapularis ticks and white- 
footed mice. The deer tick virus was reported in 2009 with a fatal outcome in a 62-yearold New York state resident with chronic lymphocytic leukemia who presented with encephalitis (Tavakoli et al, 2009).

12- Colorado Tick Fever Virus: Colorado ti-ck fever virus (genus Coltivirus, family Reov- iridae) is an acute systemic febrile illness, transmitted to humans in the western United States and Canada, Dermacentor andersoni. Colorado tick fever (CTF) is caused by the CTF virus (CTFV). The distribution of human disease corresponds to the wood tick's distribution in the mountainous areas at 4000- to 10,000-foot elevations. Transmission occurs from March to September, but peaks from April to June and transmission by blood transfusion was documented (Yendell et al, 2015).

The mean incubation period is three to four days, and $90 \%$ of patients reported tick bites or tick exposure. Fever, chills, myalgias, and prostration are common. Headache often occurs during the acute febrile phase. About $15 \%$ of patients experience a petechial or maculopapular rash and leukopenia is common. Although the acute symptoms last about a week, fever might recur several days later, fatigue was often prolonged, and 5 to $10 \%$ of children developed meningitis or encephalitis (Goodpasture et al, 1978).

Serologic tests always not positive for 10 to 14 days after symptom onset. In comparison, reverse transcriptase PCR proved diagnostic from the first day of symptoms (Johnson et al, 1997). The virus infects marrow erythrocytic precursors, which accounts for the ability to recover the virus from peripheral blood up to six weeks after illness onset.

The Colorado tick fever virus (from North America), was isolated from patients with flulike syndromes, meningitis, encephalitis, and other severe complications.

13- Another coltivirus, Eyach virus, was isolated from ticks in France and Germany and incriminated in febrile illnesses and neurologic syndromes.

14- Seadornaviruses are endemic in South- east Asia, particularly Indonesia and China. The prototype virus of the genus, Banna virus (BAV), was isolated from many mosquito species, humans with encephalitis, pigs, and cattle. Two other seadornaviruses, Kadipiro and Liao Ning, were isolated only from mosquitoes (Attoui et al, 2005). Serologic tests are often not positive for 10 to 14 days after symptom onset. In comparison, reverse transcriptase polymerase chain reaction (PCR) may be diagnostic from the first day of symptoms. The virus infects marrow erythrocytic precursors, which accounts for the ability to recover the virus from peripheral blood up to six weeks after illness onset (Attoui et al, 1998).

15- Chandipura Virus: Since the 1950's, outbreaks of encephalitis of unknown etiology and high mortality have occurred in children in India. In 2003 in Southern India, an outbreak of acute encephalitis in 329 children was associated with Chandipura virus (genus Vesiculovirus, family Rhabdoviridae). The affected children all tested negative for eight other potential viral causes including Japanese encephalitis (which is responsible for many encephalitis outbreaks in India), West Nile virus, dengue, and measles virus. Chandipura virus was identified by electron microscopy, complement fixation, and neutralization tests. Observation that $\operatorname{IgM}$ titers directed against this virus were more frequently identified after four days of illness compared to baseline values provided further evidence supporting its pathogenetic role (Jacob, 2010). It may be transmitted by sand-fly bites and has been identified in Aedes aegypti mosquitoes. Illness is characterized by the rapid onset of fever followed by vomiting, altered mental status, and seizures. Chandipura virus was isolated from sandflies in India and West Africa (Fontenille et al, 1994), which indicated a wide distribution although no human cases have been observed outside India. The mortality rate in the 2003 outbreak was $56 \%$. A similar outbreak occurred in 26 children in western India in 2004, with a 
mortality of $78 \%$ (Chadha et al, 2005). It is an arthropod borne rhabdovirus associated with acute encephalitis in children below the age of 15 years in the tropical states of India, caused the sudden death of 10 children in 2012 and an outbreak 2007 in Maharashtra. The exact mechanism allowing CHPV to invade the central nervous system (CNS) is currently poorly understood (Rajasekharan et al, 2014).

16- Toscana Virus: Toscana virus or Sandfly fever, Phlebotomus fever or Pappataci fever (genus Phelbovirus, family Bunyaviridae) is transmitted to humans in southern Europe by infected Phelbotomus sandflies. High seroprevalence rates in populations in endemic areas suggest that most infections are asymptomatic or clinically inconsequential. The incubation period is from a few days to two weeks. The disease is characterized by fever, headache, and gastrointestinal symptoms; decreased consciousness, paresis, and ocular findings may occur (Charrel et al, 2005). Despite increasing evidence of its major role in medicine as an emerging cause of CNS infections, TOSV remains an unstudied pathogen (Hukić and SalimovićBesić, 2009). Majority of clinical and epide miologic studies on Toscana virus were reported from Italy, France, Spain, Portugal and other Mediterranean countries as Kuwait, Tehran, Turkey...etc (Kadanal1, 2012). Phlebotomus species are well known in all the Mediterranean Countries (Saleh et al, 2015). The update data on TOSV circulation in the Mediterranean Countries, so in Bosnia and Herzegovina raises concern about potential implications for blood donations, because of the asymptomatic course of illness in majority of cases. Prognosis is generally favorable. CSF examination generally shows pleocytosis. Diagnosis of Toscana virus can by detection of IgM antibody by capture immunoassay of CSF, a fourfold rise in serum antibody titers against Toscana virus, or isolation of virus from or demonstration of viral antigen or genomic sequences in tissue, blood, or CSF (Di Nicuolo et al, 2005).

\section{Conclusion and Recommendations}

Viral infections of the central nervous system (CNS) result in the clinical syndromes of aseptic meningitis or encephalitis. True incidence is difficult to determine because the diagnosis may not be considered, many cases are unreported, or a specific viral etiology is never confirmed. But, these disorders occur with sufficient frequency that physicians should be familiar with the clinical manifestations, diagnostic techniques, and therapeutic options

Patients with aseptic meningitis most commonly present with fever and headache with meningiomas on examination. Patients may be lethargic but have a normal sensorium. By contrast, patients with encephalitis present with mental status changes. Patients with features of both may be considered to have meningoencephalitis. The viral encephalitis can be either primary or post-infectious, which are so difficult to differentiate on clinical grounds. Elicit a detailed sexual, travel, and exposure history (to both insect-vectors and animals). Carefully examine for generalized rashes and focal neurologic findings. Obtain neuroimaging to assess the possibility of a localized process, such as an abscess, and to look for focus that can suggest a specific etiology of encephalitis as temporal lobe involvement and HSV1. CSF examination with suspected meningitis or encephalitis is essential for diagnosis. A lymphocytic predominance is suggestive of a viral etiology; RBCs without traumatic tap is suggestive of HSV or other necrotizing viral encephalitis. The most important diagnostic consideration in patients with encephalitis is HSV since the delay in treatment can impact morbidity and mortality.

Advised to Staff-Nurses duty with the encephalitis patient must include: 1- Document hyperthermia related to the infectious process and cerebral edema as manifested by fever and tachycardia: a- Administer antimicrobial agents on time to maintain optimal blood levels, b- Monitor temperature frequently or continuously, and administer an- 
tipyretics as ordered, and c- Institute other cooling measures, such as a hypothermia blanket, as indicated. 2- Avoid risk of imbalanced fluid volume related to fever and decreased intake: a- Prevent I.V. fluid overload, which may worsen cerebral edema, bMonitor intake and output closely, and cMonitor CVP frequently. 3- Ineffective Tissue Perfusion (cerebral) related to infectious process and cerebral oedema: a- Assess LOC, vital signs, and neurologic parameters frequently. Observe for signs and symptoms of ICP (e.g., decreased LOC, dilated pupils, widening pulse pressure), b- Maintain a quite lot, calm environment to prevent agitation, which may cause an increased ICP, cPrepare patient for a lumbar puncture for CSF evaluation, and repeat spinal tap, if indicated. Lumbar puncture typically precedes neuroimaging, and d- Notify the health care authorities provider for any deterioration sign: the increasing temperature, decreasing LOC, seizure activity, or altered respirations. 4- For the acute pain related to meningeal irritation: a- Administer analgesics as ordered; monitor for response and adverse reactions. Avoid opioids, which may mask a decreasing LOC, b- Darken the room if photophobia is present, c- Assist with position of comfort for neck stiffness, and turn patient slowly and carefully with head and neck in alignment, and d- Elevate the head of the bed to decrease ICP and reduce pain. 5- For the impaired physical mobility related to prolonged bed rest: a- Implement rehabilitation interventions after admission (e.g., turning, positioning), and b- Progress from passive to active exercises based on the patient's neurologic status.

Treatment goals are to provide the supportive care. Medications may include: 1Antiviral agents, as acyclovir (Zovirax) and foscarnet (Foscavir), 2-Antibiotics if secondary bacterial infection, 3- Anti-seizure agent as phenytoin, 4- Steroids as dexamethasone to reduce brain swelling if needed, 5-Sedatives for irritability, 6- Acetaminophen for fever \& headache, and 7- Physical therapy and speech therapy may be needed if residual CNS deficits

\section{References}

Arnold, W, Altermatt, HJ, Gebbers, JO, 1984: Qualitative detection of immunoglobulins in the human endolymphatic sac. Laryngol. Rhinol. Otol (Stuttg). 63, 9:464-7.

Arrigo, NC, Adams, AP, Weaver, SC, 2010: Evolutionary patterns of eastern equine encephalitis virus in North versus South America suggest ecological differences and taxonomic revision. J. Virol. 84:1014-8.

Arya, SC, Agarwal, N, 2014: Apropos: an update on the incidence of dengue gaining strength in Saudi Arabia and current control approaches for its vector mosquito. Parasites Vectors 7, $1: 233-8$

Attoui, H, Billoir, F, Bruey, JM, de Micco, P, de Lamballerie, $X$, 1998: Serologic and molecular diagnosis of Colorado tick fever viral infections. Am. J. Trop. Med. Hyg. 59, 5:763-8.

Attoui, H, Mohd Jaafar, F, de Micco, P, de Lamballerie, $X, 2005$ : Coltiviruses and seadornaviruses in North America, Europe, and Asia. Emerg. Infect. Dis. 11, 11:1673-9.

Auguste, AJ, Pybus, OG, Carrington, CV, 2009: Evolution and dispersal of St. Louis encephalitis virus in the Americas. Infect. Genet. Evol. 9:709-12.

Bailey, JR, Williams, TM, Siliciano, RF, Blankson, JN, 2006: Maintenance of viral suppression in HIV-1-infected HLA-B*57+ elite suppressors despite CTL escape mutations. J. Exp. Med. 203: 1357-64.

Baillie, GJ, Kolokotronis, SO, Waltari, E, et al, 2008: Phylogenetic and evolutionary analyses of St. Louis encephalitis virus genomes. Mol. Phylogenet. Evol. 47:717-22.

Barrett, PN, Schober-Bendixen, S, Ehrlich, H J, 2003: History of TBE vaccines. Vaccine 21, 1:S41-8.

Brooks, TJ, Phillpotts, RJ, 1999: Interferonalpha protects mice against lethal infection with St Louis encephalitis virus delivered by the aerosol and subcutaneous routes. Antiviral Res. 41:57-60.

Burrow, JN, Whelan, PI, Kilburn, CJ, et al, 1998: Australian encephalitis in the Northern Territory: clinical and epidemiological features, 1987-1996. Aust. N Z J. Med. 28:590-6.

Calisher, CH, 1994: Medically important arboviruses of the United States and Canada. Clin. 
Microbiol. Rev. 7:89-92.

CDC, 1997: Case definitions for infectious conditions under public health surveillance. MMWR. Recomm. Rep. 46:1.

CDC, 1998: Arboviral infections of the central nervous system--United States, 1996-1997. MM WR Morb. Mortal. Wkly. Rep. 47:517.

CDC, 2001: Outbreak of Powassan encephalitis-Maine and Vermont, 1999-2001. MMWR Morb. Mortal. Wkly. Rep. 50:761-4.

CDC, 2006: Eastern equine encephalitis--New Hampshire and Massachusetts, August-September 2005. MMWR Morb. Mortal. Wkly. Rep. 55:697.

CDC, 2006: Investigation of a new diagnosis of multidrug-resistant, dual-tropic HIV-1 infection: New York City, 2005. MMWR Morb. Mortal. Wkly, Rep. 55:793-6.

CDC, 2009: Possible congenital infection with La Crosse encephalitis virus: West Virginia, 2006-2007. MMWR Morb. Mortal. Wkly. Rep. 58:4.

CDC, 2010: Tick-borne encephalitis among U. S.A. travelers to Europe and Asia- 2000-2009. MMWR Morb. Mortal. Wkly. Rep. 59:335.

Chadha, MS, Arankalle, VA, Jadi, RS, et al, 2005: An outbreak of Chandipura virus encephalitis in the eastern districts of Gujarat state, India. Am. J. Trop. Med. Hyg. 73:566-70.

Charrel, RN, Gallian, P, Navarro-Mari, JM, et al, 2005: Emergence of Toscana virus in Europe. Emerg. Infect. Dis. 11:1657-62.

Chhour, YM, Ruble, G, Hong, R, et al, 2002: Hospital-based diagnosis of hemorrhagic fever, encephalitis, and hepatitis in Cambodian children. Emerg. Infect. Dis. 8:485-90.

Deen, JL, Harris, E, Wills, B, et al, 2008: The WHO dengue classification and case definitions: time for a reassessment. Lancet 2006; 368:1706.

Deresiewicz, RL, Thaler, SJ, Hsu, L, Zamani, AA, 1997: Clinical and neuroradiographic manifestations of eastern equine encephalitis. N. Engl. J. Med. 336:1867-9.

Di Nicuolo, G, Pagliano, P, Battisti, S, et al, 2005: Toscana virus central nervous system infections in southern Italy. J. Clin. Microbiol. 43: 6186-90.

El-Bahnasawy, MM, Abdel Fadil, EE, Morsy, TA, 2013a: Mosquito vectors of infectious diseases: Are they neglected health disaster in Egypt? J. Egypt. Soc. Parasitol.. 43, 2:373-86
El-Bahnasawy, MM, Khater, MMKh, Morsy, TA, 2013b: The mosquito borne west Nile virus infection: Is it threating to Egypt or a neglected endemic disease? J. Egypt. Soc. Parasitol. 43, 1: 87-102.

El Khoury, MY, Camargo, JF, White, JL, Backenson, BP, Dupuis, AP, 2013: Potential role of deer tick virus in Powassan encephalitis cases in Lyme disease-endemic areas of New York, U.S.A. Emerg. Infect. Dis. 19, 12:1926-33.

Erwin, PC, Jones, TF, Gerhardt, RR, et al, 2002: La Crosse encephalitis in Eastern Tennessee: Clinical, environmental, and entomological characteristics from a blinded cohort study. Am. J. Epidemiol. 155:1060-4.

Fontenille, D, Traore-Lamiana, M, Trouillet, J, Leclerc, A, et al, 1994: First Isolations of Arbo-viruses from Phlebotomine Sand Flies in West Africa. Am. J. Trop. Med. Hyg. 50, 5:5704.

Gardner, JJ, Reyes, MG, 1980: Pathology. In: St. Louis Encephalitis, Monath, TP (Ed), American Public Health Association, Washington, DC. Gholam, BI, Puksa, S, Provias, JP, 1999: Pow-assan encephalitis: a case report with neuropath-ology and literature review. CMAJ 161:1419-22.

Golomb, MR, Durand, ML, Schaefer, PW, et al, 2001: A case of immunotherapy-responsive eastern equine encephalitis with diffusion-weighted imaging. Neurology 56:420-4.

Goodpasture, HC, Poland, JD, Francy, DB, et al, 1978: Colorado tick fever: clinical, epidemiologic, and laboratory aspects of 228 cases in Colorado in 1973-1974. Ann. Intern. Med. 88:303-5.

Gossner, CM, Marrama, L, Carson, M, Allerberger, F, Calistri, P, 2017: West Nile virus surveillan- ce in Europe: moving towards an integrated animal-human-vector approach. Euro Surveill. May 4; 22 (18). pii:30526.

Gubler, DJ, 2007: The continuing spread of West Nile virus in the western hemisphere. Clin. Infect. Dis. 45:1039-42.

Haglund, M, Günther, G, 2003: Tick-borne encephalitis--pathogenesis, clinical course and long-term follow-up. Vaccine 21, 1:S11-8.

Halstead, SB, 2007: Dengue. Lancet 370:16449.

Halstead, SB, Jacobson, J, 2003: Japanese ence-phalitis. Adv. Virus Res. 61:103-6.

Heinz, FX, Stiasny, K, Holzmann, H, et al, 
2013: Vaccination and tick-borne encephalitis, central Europe. Emerg. Infect. Dis. 19:69-74.

Hinten, SR, Beckett, GA, Gensheimer, KF, et al, 2008: Increased recognition of Powassan encephalitis in the United States, 1999-2005. Vector Borne Zoonotic Dis. 8:733-40.

Hoogstraal, H, 1954: A preliminary, annotated list of ticks (Ixodoidea) of the Anglo-Egyptian Sudan. J. Parasitol. 40, 3:304-10

Hjalmarsson, A, Blomqvist, P, Skoldenberg, B, 2007: Herpes simplex encephalitis in Sweden, 1990-2001: incidence, morbidity, and mortality. Clin. Infect. Dis. 45:875-80.

Holzmann, H, 2003: Diagnosis of tick-borne encephalitis. Vaccine 21, 1:S36.

Hotez, PJ, 2018: The rise of neglected tropical diseases in the "New Texas" PLoS Negl. Trop. Dis. Jan; 12(1): e0005581.

Hukić, M, Salimović-Besić, I, 2009: Sand-flyPappataci fever in Bosnia and Herzegovina: New-old disease. Bosn. J. Basic Med. Sci. 9, 1: 39-43.

Humphrey, JM, Cleton, NB, Reusken, CB, GI esby, MJ, Koopmans, MP, 2016: Dengue in the Middle East and North Africa: A systematic review. PLoS Negl. Trop. Dis. Dec 7;10(12): e000 5194.doi: 10.1371/

Jacob, JT, 2010: Chandipura virus: What we know \& do not know? Indian J. Med. Res 132: 125-30.

Johnson, A, Karabatsos, N, Lanciotti, R, 1997: Detection of Colorado tick fever virus by using reverse transcriptase PCR and application of the technique in laboratory diagnosis. J. Clin. Microbiol. 35:1203-9.

Johnson, GD, Eidson, M, Schmit, K, et al, 2006: Geographic prediction of human onset of West Nile virus using dead crow clusters: an evaluation of year 2002 data in New York State. Am. J. Epidemiol. 163:171-8.

Kadanalı, A, 2012: An overview of Toscana virus infections. Mikrobiyol. Bul. 46, 1:144-52.

Kaiser, R, 1999: The clinical and epidemiological profile of tick-borne encephalitis in southern Germany 1994-98: a prospective study of 656 patients. Brain 122, 11:2067.

Kaiser, R, 2008: Tick-borne encephalitis. Infect. Dis. Clin. North Am. 22:561-8.

Khor, BS, Liu, JW, Lee, IK, Yang, KD, 2006: Dengue hemorrhagic fever patients with acute abdomen: clinical experience of 14 cases. Am. J. Trop. Med. Hyg. 74: 901-6.
Kienzle, N, Boyes, L, 2003: Murray Valley ence-phalitis: case report and review of neuroradiolo-gical features. Australas Radiol. 47:61-4. Kindberg E, Mickiene A, Ax C, et al, 2008: A deletion in the chemokine receptor 5 (CCR5) gene is associated with tick-borne encephalitis. J. Infect. Dis. 197:266.

Kramer, LD, Chandler, LJ, 2001: Phylogenetic analysis of the envelope gene of St. Louis encephalitis virus. Arch. Virol.146:2341.

Kroeger, A, Nathan, M, Hombach, J, 2004: Dengue. Nat. Rev. Microbiol.2:360-4

Lessell, S, Collins, TE, 2003: Ophthalmoplegia in Powassan encephalitis. Neurology 60:172630.

Lindquist, L, Vapalahti, O, 2008: Tick-borne encephalitis. Lancet 371:1861.

Mackenzie, JS, Lindsay, MD, Coelen, RJ, et al, 1994: Arboviruses causing human disease in the Australasian Zoogeographic Region. Arch. Virol. 136:447-9.

Mackenzie, JS, Williams, DT, Smith, D, 2007: Japanese encephalitis virus: The geographic distribution, incidence, and spread of a virus with a propensity to emerge in new areas. In: Emerging Viruses in Human Populations, Tabor, E (Ed), Elsevier.

Martin, DA, Noga, A, Kosoy, O, et al, 2004: Evaluation of a diagnostic algorithm using immunoglobulin $M$ enzyme-linked immunosorbent assay to differentiate human West Nile Virus and St. Louis Encephalitis virus infections during the 2002 West Nile Virus epidemic in the United States. Clin. Diagn. Lab. Immunol. 11: 1130-9.

May, F, Li, L, Zhang, S, et al, 2008: Genetic variation of St. Louis encephalitis virus. J. Gen. Virol. 89:1901-4.

Mazyad, SAM, Morsy, TA, Fekry, AA, Farrag, AMK, 1999: Mites infesting two migratory birds, Coturnix c. coturnix (quail or simman) and Sturnus v.vulgaris (starling or zarzour) with reference to avian zoonosis. J. Egypt. Soc. Parasitol. 29, 3:745-61.

McBride, WJ, Mullner, H, LaBrooy, JT, Wronski, I, 1998: The 1993 dengue 2 epidemic in North Queensland: A serosurvey and comparison of hemagglutination inhibition with an ELISA. Am. J. Trop. Med. Hyg.59:457-62.

McJunkin, JE, de los Reyes, EC, Irazuzta, JE, et al, 2001: La Crosse encephalitis in children. N. Engl. J. Med. 344:801-4. 
McJunkin, JE, Khan, R, de los Reyes, EC, et al, 1997: Treatment of severe La Crosse encephalitis with intravenous ribavirin following diagnosis by brain biopsy. Pediatrics 99:261-4.

Mickienė, A, Pakalnienė, J, Nordgren, J, CarIsson, B, Hagbom, M, et al, 2014: Polymorphisms in chemokine receptor $5 \&$ Toll-like receptor 3 genes are risk factors for clinical tickborne encephalitis in the Lithuanian population. PLoS One. Sept 16;9(9):e106798. doi: 10.1371/ journal.pone. 0106798 .

Mikhail, MW, Al-Bursheed, KhM, Abd ElHalim, AS, Morsy, TA, 2009: Studies on mosquito borne diseases in Egypt and Qatar. J. Egypt. Soc. Parasitol. 39, 3:745-56.

Morsy, TA, 2018: Aedes aegypti and dengue virus infections. J. Egypt. Soc. Parasitol. 48, 1: 183-96.

Panzig, B, Herrmann, R, Döhner, L, 1978: Demonstration of $\operatorname{IgM}$ antibodies in influenza virus infections. Arch. Exp. Veterinarmed. 32, 4: 1511-7.

Persijn, L, Decavele, AS, Schouwers, S, Devreese, K, 2011: Evaluation of a new set of automated chemiluminescense assays for anticardiolipin and anti-beta2-glycoprotein I antibodies in the laboratory diagnosis of the antiphospholipid syndrome. Thromb. Res. 128, 6:565-9.

Petersen, LR, Hayes, EB, 2008: West Nile virus in the Americas. Med. Clin. North Am. 92: 1307-12.

Rahal, JJ, Anderson, J, Rosenberg, C, et al, 2004: Effect of interferon-alpha $2 b$ therapy on St. Louis viral meningoencephalitis: Clinical and laboratory results of a pilot study. J. Infect. Dis. 190:1084-9.

Rajasekharan, S, Rana, J, Gulati, S, Gupta, V, Gupta, S, 2014: Neuroinvasion by Chandipura virus. Acta Trop. 135:122-6.

Reisen, WK, 2003: Epidemiology of St. Louis encephalitis. In: Flaviviruses: Detection, Diagnosis, and Vaccine Development, Chambers, TJ, Monath, TM (eds.), Adv. Virus Res. 61:139-42.

Reisen, WK, Lothrop, HD, Wheeler, SS, et al, 2008: Persistent West Nile virus transmission and the apparent displacement St. Louis encephalitis virus in southeastern California, 20032006. J. Med. Entomol. 45:494-9.

Rigau-Perez, JG, 1998: The early use of breakbone fever (Quebranta huesos, 1771) and dengue (1801) in Spanish. Am. J. Trop. Med. Hyg. 59: 272-8.
Sakaguchi, M, Nakashima, K, Takahashi, H, et al, 2001: Anaphylaxis to Japanese encephalitis vaccine. Allergy 56:804-8.

Saleh, AM, Labib, A, Abdel-Fattah, MS, AlAttar, MB, Morsy, TA, 2015: Sand-fly Phlebotomus papatasi (Phlebotominae): A general review with special reference to zoonotic cutaneous leishmaniasis in Egypt. J. Egypt. Soc. Parasitol. 45, 3: 525-44

Sejvar, JJ, Bode, AV, Curiel, M, Marfin, AA, 2004: Post-infectious encephalomyelitis associated with St. Louis encephalitis virus infection. Neurology 63:1719.

Sewell, DL, 2003: Laboratory safety practices associated with potential agents of biocrime or bioterrorism. J. Clin. Microbiol. 41, 7:2801-3.

Süss, J, 2003: Epidemiology and ecology of TBE relevant to the production of effective vaccines. Vaccine 21, 1:S19-22.

Tavakoli, NP, Wang, H, Dupuis, M, et al, 2009: Fatal case of deer tick virus encephalitis. N. Engl. J. Med. 360:2099-302

Trent, DW, Monath, TP, Bowen, G, et al, 1980: Variation among strains of St. Louis encephalitis virus: Basis for a genetic, pathogenic and epidemiologic classification. Ann. N. Y. Acad. Sci. 354:21-9.

Vilibić-Čavlek, T, Barbić, L, Pandak, N, PemNovosel, I, Stevanović, V, et al, 2014: Tick-borne encephalitis virus: epidemiological and clinical picture, diagnosis and prevention. Acta. Med. Croatica. 68, 4/5:393-404

WHO, 1997: Dengue hemorrhagic fever: diagnosis, treatment, prevention, and control. $2^{\text {nd }}$ edition, Geneva, Switzerland.

WHO, 2014: Growing threat of viral haemorrhagic fevers in the Eastern Mediterranean Region: a call for action Regional Office for the Eastern Mediterranean, Cairo. http://applications /emro.who.int/docs/em_rc544_en.pdf?ua=1.

WHO, 2015: Dengue fever-Egypt http://www. who.int/csr/don/12-november-2015-dengue/en.

Yahr, MD, 1972: Treatment of Parkinsonism: Current concepts. Med. Clin. North Amer. 56, 6: 1377-92.

Yendell, SJ, Fischer, M, Staples, E, 2015: Colorado tick fever in the United States, 20022012.Vector Borne Zoonotic Dis. 15, 5:311-6.

Zajkowska, JM, 2010: Transmission and circulation of tick borne pathogens (TBE and Lyme borreliosis) and the role of changing environment. Przegl. Epidemiol. 64, 4:525-31. 